\title{
COMPLIMENTS AND RESPONSES DURING CHINESE NEW YEAR CELEBRATIONS IN SINGAPORE ${ }^{1}$
}

\author{
Cher Leng Lee
}

\begin{abstract}
This paper examines the act of complimenting and responding to compliments among Singapore Chinese. To this end, I explored naturally occurring compliment exchanges during the Chinese New Year (CNY) period. These exchanges are not only gender-sensitive, but age- and generation-sensitive as well. The CNY celebrations are governed by certain conventions, exchanging compliments being one of them. The conventional setting helps us understand the functions of compliments and the nature of their responses better, thus avoiding overgeneralizations. Compliments and their responses in the CNY context appear to play an important mainly phatic role. This study suggests that (a) married females pay and receive most compliments and (b) the most common compliment topic centers on their children's academic achievement and potential career success rather than appearance (Holmes 1988) or possessions (Herbert 1991). In addition, most responses are of the non-acceptance type with downgrading, which is in line with findings from other researchers (see, e.g., Gu 1990; Chen 1993). A survey carried out on these nonacceptance responses shows that informants understand them as being largely conventional and formalistic rather than literal in nature, probably due to the conventional setting. This speech event of compliments and their responses is a mirror of cultural values (Manes 1983), revealing that the Chinesespeaking community of Singapore places high importance on children's socio-economic success and practices conventional humility.
\end{abstract}

Keywords: Compliment and responses; Singapore; Chinese; CNY; Politeness; Convention.

\section{Introduction}

The speech act of complimenting has received a lot of scholarly attention, especially in the West. This paper studies compliments and their responses in a non-Western setting. It examines the occurrence of this speech event during the Chinese New Year (CNY), which is the most popular traditional festival celebrated by the Chinese community in Singapore. These exchanges are carried out in Mandarin and in Southern Chinese dialects such as Hokkien, Cantonese and Teochew, interspersed sometimes with English and Malay (Lee 2003). The study of the speech event of compliments and their responses in a specific cultural context is important, as it can be a mirror of cultural values, revealing sociolinguistic principles underlying the nexus between language and

\footnotetext{
${ }^{1}$ I am indebted to Maria Sifianou and the anonymous reviewers of Pragmatics for all the constructive comments and suggestions. Needless to say, any remaining shortcomings are my own.
} 
culture, between interaction and values, and between surface forms and their social functions.

This paper contributes to the study of compliments and compliment responding in the following ways: Firstly, methodologically, it uses naturally occurring data rather than questionnaires (Ye 1995) to ensure findings which will reflect what people actually do in their interactions. ${ }^{2}$ Using a corpus of nearly 300 naturally occurring compliment exchanges, an analysis is provided for the distribution of compliment topics and their responses among married females, younger single females, married males, and younger single males. Secondly, these compliment exchanges occur in a specific setting governed by certain conventions which influence the construction and function of compliments and of their responses, enabling the analyst to avoid overgeneralizations.

This paper shows that compliments and their responses in the CNY context play an important mainly phatic role. The analysis suggests that (a) married females (Fs) with children are the main givers and recipients of compliments. They are the ones who should know best how to behave according to Chinese social expectations and conventions, and (b) the main topic of compliments in this context is each other's children. This includes the children's academic achievements, career success, having children (or grandchildren) of their own, and demonstration of filial piety (which is an important Confucian ethic). Academic success presumably leads to better career opportunities, which may in turn lead to better income, more possessions, and a more comfortable lifestyle for both children and parents. Thus, socioeconomic status is important along with marriage and having children, which is in turn associated with that status because of the cultural expectation that children will assume responsibility for the financial security of their parents in old age. In addition, most responses are of the nonacceptance type with downgrading, which conforms to findings from other research (see, e.g., Gu 1990; Chen 1993). A survey carried out on these non-acceptance responses shows that informants understand them as being largely conventional in nature.

More specifically, the study of compliments and their responses in a particular social context such as CNY shows that some traditions and conventions will be retained, and changes will be slower than is the case for some other kinds of daily interactions. According to Tang and Zhang (2009), the Chinese in Australia accept compliments more easily than is normally considered appropriate in Chinese culture, a fact which probably reflects Australian influence ${ }^{3}$. The compliments in this study are conventional and do not exhibit the kind of creativity found in Greek (Sifianou 2001). This speech event of compliments and their responses is a mirror of cultural values (Manes 1983). It shows that the general Chinese-speaking community of Singapore practices conventional humility and places high importance on children's socio-economic success.

This paper addresses the following issues: Who pays and receives most compliments, what the main topics of compliments are, and what types of responses

${ }^{2}$ For instance, Yuan (2002) used natural data and data from DCTs (discourse completion tests) and found that "acceptance" was $50 \%$ in the DCT data and only $31 \%$ in the natural data. This means that people say one thing naturally but when specifically asked what they would or should do in a given situation, they respond the way they believe the researcher wants them to.

${ }^{3}$ However, this data is from DCTs and not naturally occurring data. 
compliments receive. The paper is organized as follows: The next section explains the methodology of this study. Section 3 discusses the act of complimenting, the main givers and recipients and the main topics of compliments, with particular attention to the gender and age of compliment givers and receivers. Section 4 discusses three dominant types of responses to compliments, which are 'non-acceptance', 'acceptance' and 'deflect or evade'. Section 5 focuses on the 'non-acceptance response' as a conventionalized act. Section 6 discusses the 'acceptance' responses. Section 7 shows how the 'deflect or evade' responses are indirect ways of rejecting compliments. Section 8 concludes the paper.

\section{Setting and methodology}

\subsection{Setting}

Singapore is a cosmopolitan society of about Chinese $74.2 \%$, Malay $13.4 \%$, Indian $9.2 \%$, other 3.2\% (Singapore Department of Statistics 2009). English is the main working language, followed by Mandarin Chinese. I have chosen CNY (also known as the Lunar New Year) as the setting for collecting compliments as it is the most important festive season among ethnic Chinese Singaporeans when relatives and friends visit each other and also because it is customary for people to exchange a number of compliments in these settings. It is thus a site rich in naturally occurring compliments.

CNY usually takes place about a month after the New Year of the Gregorian calendar. In Singapore, the first two days of the $\mathrm{CNY}^{4}$ are public holidays. During these two days, relatives and friends usually wear red clothes (or other auspicious colors such as pink, orange, yellow, purple, never black) and go to visit one another. The tradition is for the younger generation to visit members of the older generation.

In the morning of the first day of CNY, most families congregate in the home of the oldest living paternal or maternal grandparents or great-grandparents of the current youngest generation to pay their respects. For example, if the paternal grandparents are living with the eldest uncle from the father's side, on the first day of CNY, families of other siblings in the same family will visit this uncle's family to pay their respects to the grandparents and the eldest uncle. In cases where the grandparents are no longer living, they will visit their uncles or aunts (who are of higher birth order than their parents) or elder brothers or sisters. It is customary for the younger siblings to visit the older ones. Respect for the older generation and older siblings is very important in Chinese society.

It is the custom for the older generation to distribute red packets or hongbao ${ }^{5}$ (which contain cash) to the singles of the younger generation (regardless of age) wishing them good luck, success (for students) and prosperity (for those working) for the New Year. During these visits, people will greet one another with conventional greetings in Mandarin such as 'Xinnian kuaile' (Happy New Year) or 'Wanshi ruyi' (May your wishes be fulfilled), in English 'Happy New Year', in Teochew 'Singjia juyi' (May you have as you wish this New Year), or in Cantonese 'Kong hei fatt choy' (May

\footnotetext{
${ }^{4}$ Traditionally, there are 15 days of CNY.

${ }^{5}$ This is also called yasuiqian 压岁钱 in China. It is given to children to ward off evil.
} 
you be prosperous). It is also a time when it is polite to compliment each other (for relatives), and to say auspicious things about relatives and friends, most of whom one meets only once or twice a year. These compliments and responses reveal the value system of these Singaporean Chinese. This paper focuses on compliments and their responses and explains what motivates these responses.

\subsection{Methodology}

This section explains the methodology of collecting the two sets of data for this study. The first set consists of compliments and responses collected during CNY. The second set consists of a survey on the non-acceptance responses of the compliments. Jucker (2009) compares the different kinds of methodologies in doing research on compliments. Some studies on complimenting have been carried out using questionnaires (see, e.g. Chen 1993; Ye 1995). However, as has repeatedly been emphasized, such constructed data may not reflect exactly what happens in actual encounters. Thus, to capture genuine exchanges as accurately as possible, the first set of data of this study was either tape-recorded or jotted down as soon as the exchange had taken place. The compliments and their responses were collected by 58 final-year university undergraduates (49 female and 9 male). They were instructed to observe and record the interactions during $\mathrm{CNY}$ visits. This means that their presence did not affect the validity of the data as they were not participating but mainly observing and recording.

The students had been taught how to record natural conversations using the tape recorder and to transcribe them using Du Bois' (1993) conventions. They were asked to record five complimenting interactions during the span of the two days of CNY visits. They were instructed to turn on the tape recorder once they entered the house of the relatives they were visiting or when relatives came to visit them. Since such settings are not ideal for tape-recording, as the speech of many others would drown out that of the subjects, the students were given the option of jotting down the compliments and responses as soon as they heard them. They were also asked to note down the gender, age, and relationships between the complimenters and the complimentees. ${ }^{6}$

During CNY visits, a family or a group of visitors may arrive while another family who has visited for some time is ready to take leave. Given this dynamic social setting, it is not possible for the students to take note of the total number of people in the setting because it keeps changing. A student is only able to note the number of people in the immediate group of people he/she is involved in. It may be a small group among the grandparents and his/her family, or it may be a bigger group consisting of the student's uncle and aunt and their children. There are approximately five people involved in small-group interactions. Given that there are 58 students, there are approximately a total of 300 people involved in all these small groups.

Most of the complimenters are mothers whose ages range from about thirty to fifty years old; they are also the ones who receive the most compliments. They are referred to as ' $\mathrm{F}$ ' (females with children) in this paper. Corresponding to ' $\mathrm{F}$ ' are males

\footnotetext{
${ }^{6}$ At a later stage, the students had to explain in class how they had collected their data and to share them in the tutorials.
} 
who have children and they are referred to as ' $M$ '. Females who are not married and are mostly still in tertiary or secondary schools are referred to as ' $\mathrm{f}$ ' (females without children). The age of ' $\mathrm{f}$ ' ranges from birth to over twenty years of age; the corresponding group of males are ' $\mathrm{m}$ '. The compliments and responses are gendersensitive as well as age- and generation- sensitive. The total number of complimenters is 157 , including $90 \mathrm{~F}, 44 \mathrm{f}, 14 \mathrm{M}$ and $9 \mathrm{~m}$. The total number of complimentees is 166 , including $76 \mathrm{~F}, 54 \mathrm{f}, 20 \mathrm{M}$ and $16 \mathrm{~m}$.

The majority of compliment responses fall into the non-acceptance category. In order to find out whether the non-acceptance responses to compliments are conventional surface responses or true disagreements with the compliments, a survey was carried out to find out the intuitive judgment of native speakers. A class of 250 first-year students majoring in Chinese Studies was each given 16 sets of compliments and their responses. These students were told that these were compliments and responses collected during CNY visits. The compliments and responses were given as adjacency pairs with information on the speakers' relationship, e.g. Complimenter is Mum's sister, complimentee is the niece, etc. The students were instructed to judge according to their intuition whether the non-acceptance responses were conventional or represented genuine non-acceptances. If they thought that a non-acceptance response was sincere, they would circle the answer 'Genuine non-acceptance'; if they thought that the response was a conventional one, they would circle the 'Not genuine non-acceptance' option. The results of this survey are given and discussed in detail in Section 5.2.

\section{Compliments}

This section discusses the function and patterns of givers, recipients and topics of compliments. Compliments should be studied in specific contexts so that their function in the particular setting and speech community becomes apparent. The most commonly recognized function of compliments is the expression and maintenance of solidarity between interlocutors (Wolfson and Manes 1980; Wolfson 1983; Herbert 1989). However, Jaworski (1995) has argued that Polish compliments may also be used in a manipulative or instrumental way, in which case they are only procedurally solidary but not relationally solidary. ${ }^{7}$ In this paper, the setting of the compliments is during a festive season when relatives meet one another. Since most of these relatives usually meet only on such occasions and they are not on intimate terms, it is common to exchange compliments to break the silence. So compliments in these settings function as a kind of small talk to create amicable relations. The topics used usually involve admiring children, appearances, or homes (Boyle 2000). Thus complimenting appears to be an aspect of phatic communion that contributes to social cohesiveness, defusing 'the potential hostility of silence in situations where speech is conventionally anticipated' (Laver 1981: 301, 1975).

\footnotetext{
${ }^{7}$ Relational solidarity in compliments refers to genuine admiration with a view to establishing or reinforcing solidarity between the complimenter and the complimentee. Procedural solidarity refers to the employment of compliments as a means to another end; for example, in the case of Polish compliments, this notion refers to using them in a manipulative or instrumental fashion to obtain information regarding the source and /or price of the complimented object.
} 


\subsection{Females are the main givers}

In Holmes's $(1988,1995)$ gender-preferential study of compliments, it has been shown that New Zealand women compliment each other more often than they compliment men or than men compliment each other. Wolfson $(1983,1984)$, Lee (1990) and Sifianou (2001) also find that women give and receive more compliments than men do. This is also true for this data which shows that in this society, women with children (F) are the main givers and recipients of compliments. More specifically, the $\mathrm{F}$ group pays most compliments $(57.5 \%)$, followed by $\mathrm{f}(23.6 \%)$, then $\mathrm{M}(11.2 \%)$ and last comes the $\mathrm{m}$ group $(7.7 \%)$. The total number of compliments given by females is $81 \%$ whereas males paid only $19 \%$. The highest number of recipients of compliments is also $\mathrm{F}(43.8 \%)$, followed by $\mathrm{f}(32.6 \%)$, then $\mathrm{m}(12.9 \%)$ and the lowest being $\mathrm{M}(10.7)$. Together, the females ( $\mathrm{F}$ and $\mathrm{f}$ ) receive $76.4 \%$ compliments while the males $(\mathrm{M}$ and $\mathrm{m}$ ) receive only $23.6 \%$.

Studies have shown that compliments occur more often between interlocutors of the same gender, especially in female - female interactions in American English (Knapp et. al. 1984), New Zealand English (Holmes 1988), and Chinese (Ye 1995). However, in receiving compliments, $\mathrm{F}, \mathrm{f}, \mathrm{m}$ all receive most compliments from $\mathrm{F}$, except for $\mathrm{M}$ who receive most compliments from $\mathrm{M}$. This suggests, perhaps, that it is not acceptable for $\mathrm{F}$ to compliment $\mathrm{M}$ in this particular speech community.

\subsection{Children's academic performance and socioeconomic status}

Manes' (1983) data on American English and Holmes's (1988, 1995) data on compliments in New Zealand both show that the vast majority of compliments fall into the categories of personal appearance, accomplishments, and new acquisitions. Holmes (1988) shows that $61 \%$ of the compliments relate to appearance. Herbert's study (1997) of Polish compliments shows that due to scarcity of commodities in Poland at the time of the field research, compliments on possessions reached about $50 \%$ in his sample. The present data shows that the favorite topic of compliments among Singapore Chinese centers around children's academic success, career success, financial independence, and progress in starting a family of their own.

56 out of a total of 91 compliments (i.e. 62\%) between Fs are made up of compliments on children. Fs compliment each other on the following aspects of their children in descending order: (1) academic achievement, (2) financial independence, (3) getting married and having children, and (4) being filial to parents. The first two items show that children's success is tied to academic performance and socioeconomic status. Table 1 shows the range of topics of compliments and their corresponding percentages.

Table 1. Compliment topics: complimenters and receivers' gender and generation (sample size of compliments $=290$ )

\begin{tabular}{|c|c|c|c|c|c|c|c|c|c|c|c|c|c|c|c|c|c|}
\hline $\begin{array}{l}\text { Complimenters } \\
\text { Receivers }\end{array}$ & $\begin{array}{l}\mathbf{F}_{-} \\
\mathrm{F}\end{array}$ & $\begin{array}{l}\text { F- } \\
\mathrm{f}\end{array}$ & $\begin{array}{l}\mathrm{F}- \\
\mathrm{M}\end{array}$ & $\begin{array}{l}\text { F- } \\
\text { m }\end{array}$ & $\begin{array}{l}\text { M- } \\
\text { F }\end{array}$ & $\begin{array}{l}\text { M- } \\
\text { f }\end{array}$ & $\begin{array}{l}\text { M- } \\
\text { M }\end{array}$ & $\begin{array}{l}\text { M- } \\
\text { m }\end{array}$ & $\begin{array}{l}\mathbf{f}- \\
\mathrm{F}\end{array}$ & $\begin{array}{l}f- \\
f\end{array}$ & $\begin{array}{l}\mathrm{f}- \\
\mathrm{M}\end{array}$ & $\begin{array}{l}\mathrm{f}- \\
\mathrm{m}\end{array}$ & $\begin{array}{l}\mathbf{m}- \\
\mathrm{F}\end{array}$ & $\begin{array}{l}\mathrm{m}- \\
\mathrm{f}\end{array}$ & $\begin{array}{l}\mathrm{m}- \\
\mathrm{M}\end{array}$ & $\begin{array}{l}\mathrm{m}- \\
\mathrm{m}\end{array}$ & Total $(\%)$ \\
\hline \multicolumn{18}{|c|}{ Compliment topics } \\
\hline Children & & & & & & & & & & & & & & & & & $123(42)$ \\
\hline Children & 56 & 4 & 4 & & 4 & & 3 & & 7 & 2 & & 1 & & & & & 81 \\
\hline Academic & & 9 & & & & 3 & & 2 & & 7 & & & & 1 & & 1 & 23 \\
\hline
\end{tabular}




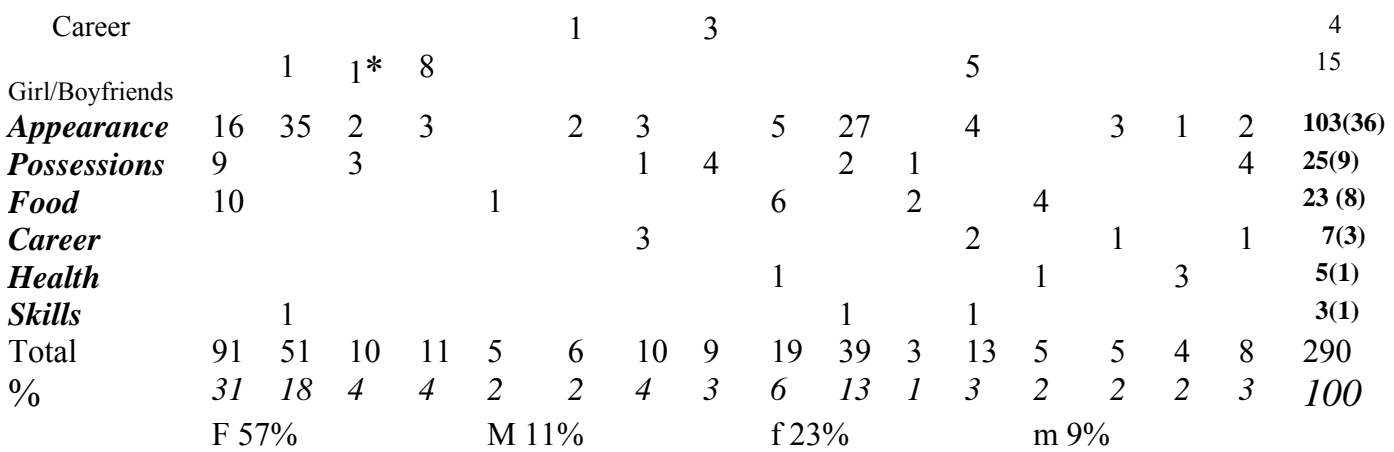

$\mathrm{F}=$ females with children, $\mathrm{M}=$ males with children, $\mathrm{f}=$ single females, $\mathrm{m}=$ single males

*In this example, $\mathrm{F}$ is complimenting M's child's Girl/Boyfriend.

In example (1), a female compliments her sister-in-law on the latter's children being university undergraduates comparing them to her own, who are 'dumb', the implication being that her children should also be studying at university but have not been able to do so. In this example, we also observe a salient feature of CNY compliments: The complimenter denigrates his or her own children to show that the complimentee's children are better. By belittling one's own child, the complimenter is giving positive face to the complimentee. The implicature here is: 'My child is worse compared to your child', which implies that 'I am worse than you'; therefore, 'you are better off than me'.

(See appendix for list of abbreviations).

(1) (spoken in Hokkien)

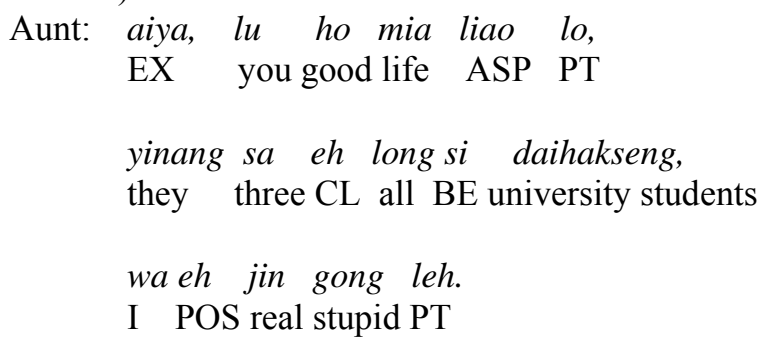

'Aiya, you have a good life now, all your (daughters) are university students while mine are so dumb.'

\subsection{Appearance}

The Singapore data shows that compliments on physical appearance are mainly given by $\mathrm{F}$ to $\mathrm{f}$, followed by $\mathrm{f}$ complimenting their peers, then $\mathrm{F}$ complimenting their peers. Interestingly, $\mathrm{M}$ and $\mathrm{m}$ neither paid nor received any compliments on appearance. This pattern is similar to the New Zealand data, which shows that women are complimented on their appearance more often than men: Over half (57\%) of all the compliments women received related to aspects of their appearance. New Zealand women give compliments on appearance more than men do, so that $61 \%$ of all the compliments between women related to appearance, compared to only $36 \%$ of the compliments 
between males. Men, by contrast, prefer to compliment other men, but not women, on their possessions (Holmes 1995).

Holmes (1988: 456) mentions that "Compliments on a person's appearance may be felt to presume an intimacy which could be regarded as inappropriate in some crosssex interaction". Elsewhere Holmes (1995: 131) suggests that "compliments on appearance cause some men embarrassment". Perhaps for these reasons, males hardly engage in such compliments. She argues that New Zealand men are more likely to interpret compliments as Face Threatening Acts (Brown and Levinson 1987) than women, who use them predominantly for maintaining solidarity. Cross-cultural research between French and American English shows that the French speakers responded with embarrassment and discomfort when they were complimented on their appearance by Americans (Wieland 1995).

According to Jaworski (1995), in Polish society, most compliments on female appearance are on one's new hairstyle. However, the Singapore CNY data shows that a great majority of compliments on appearance relate to weight loss. This reflects a society that considers losing weight as a positive attribute, especially for the female gender. In the Singapore data, when F compliments f on looking more beautiful because of having lost weight, a common follow-up is a question concerning any romantic attachment, supposedly showing concern for her well-being. This is seen in example (2) where an Aunt is complimenting a younger female.

$$
\begin{aligned}
& \text { Second Aunt: xianzai bijiao miaotiao, piaoliang le lo, } \\
& \text { now compare slim pretty ASP PT } \\
& \text { you nan pengyou le ma? } \\
& \text { have boy friend ASP QN }
\end{aligned}
$$

In Brown and Levinson's terms, asking whether one has a boyfriend will be a clear face-threatening act, threatening their negative aspect of face since it intrudes into the private life of the hearer. However, in Singapore these questions are very common, especially when relatives meet one another once a year over CNY. In this context, they can be interpreted as showing concern for the hearer since marriage is also an important institution in this speech community. For Brown and Levinson (1987: 61), 'negative face' refers to an individual's need to be free from external impositions. Chinese face (mianzi) however, echoes the Confucian tradition that advocates subordinating the individual to the group or community, and regards self-cultivation as an act of communicating with, and sharing in, an ever-expanding circle of human-relatedness ( $\mathrm{Tu}$ 1985: 249).

\subsection{Socioeconomic status and other topics}

Under the category of 'academic' (see table 5), $\mathrm{f}$ and $\mathrm{m}$ are complimented on their ability to study in prestigious schools or at the university. These compliments are also followed with comments that once they graduate from university, they will earn more money and their parents will have a good and comfortable life (hao ming). In this 
context, 'academic success' translates to better 'careers', which supposedly brings higher earning power to gain more 'possessions' such as houses and cars, in other words, producing a more comfortable lifestyle for themselves and for their parents. ${ }^{8}$ Thus, these three topics - academic success, career and possessions - together constitute socioeconomic success. Socioeconomic status is important especially to males. This explains why when the compliment-stingy Ms offer compliments at all, the topic is mostly regarding new, higher-paying jobs and job promotions. In example (3), an uncle compliments his nephew on the prospect of his upcoming graduation and ability to start earning money.

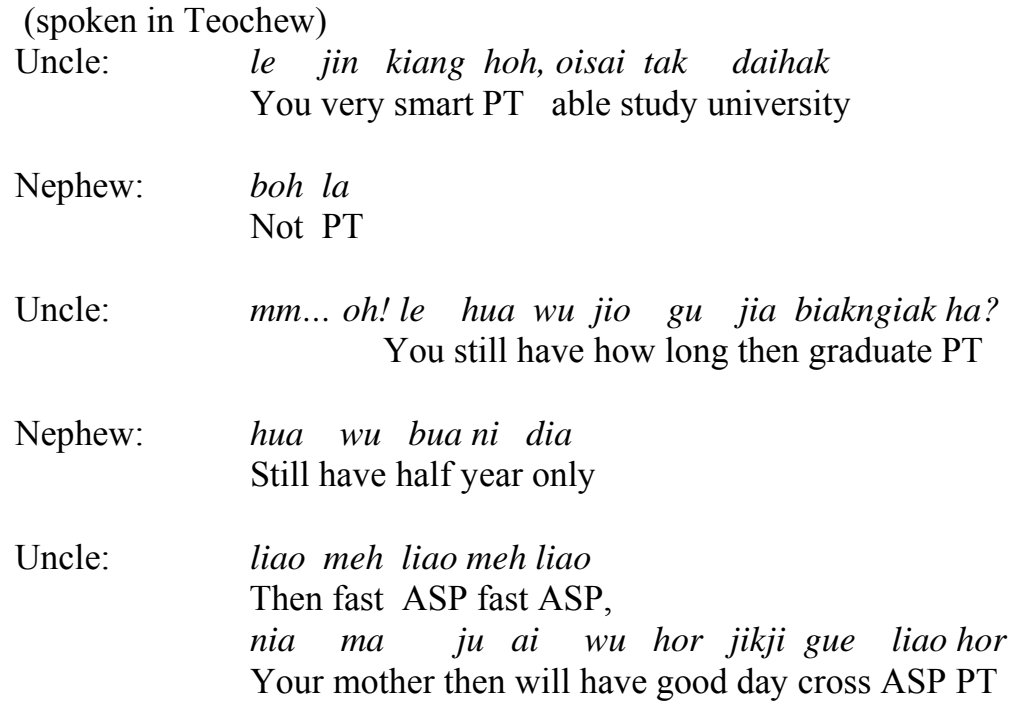

Uncle: You are very smart to be able to study in the university.

Nephew: Not really.

Uncle: How long more before you graduate?

Nephew: Only half a year.

Uncle: That's soon, your mum will have good days then.

Food usually attracts compliments during CNY when relatives and friends visit and sometimes have a meal together. These are usually directed towards the Fs who have done the cooking. In the Singapore CNY context, when food is complimented, the compliment is typically understood as an indirect way of asking for more of the item. In some contexts, compliments can function as indirect requests (Holmes 1988: 448; Jaworski 1995). ${ }^{9}$

Compliments from $\mathrm{F}$ to $\mathrm{m}$ are rather limited, but when they occur, they usually refer to the appearance of the young men's girlfriends. The topic of health figures prominently in $\mathrm{m}$ to $\mathrm{M}$ interaction, which shows that probably $\mathrm{M}$ value health most.

${ }^{8}$ In this society, children are expected to 'repay' their parents once they start earning, by giving them a monthly stipend from their salary.

${ }^{9}$ The French also appear more comfortable when receiving compliments on food than on appearance (Wieland 1995). 
These topics show that the different genders and generations esteem different things. It is important that one knows what to compliment on when addressing members of different gender and generation; being able to compliment appropriately demonstrates communicative competence.

\section{Responses}

Using Pomerantz's (1978) discussion as a starting point and Holmes's $(1988,1995)$ analysis of New Zealand data, three broad categories of compliment response are used to describe the present corpus: ACCEPTANCE, NON-ACCEPTANCE, and DEFLECT or EVADE. Though not always mutually exclusive, these categories account satisfactorily for the great majority of our examples. With a total sample size of 290 responses, the highest category of responses is Non-acceptance $(53.0 \%)$, followed by the Deflect or Evade category (24.2\%) and the Acceptance category (22.8\%). Gu (1990) and Chen (1993) have also found that non-acceptance is a common response among the Chinese. Accepting a compliment readily would sound as self-praise. ${ }^{10}$

The different ways of Non-Acceptance (53.0\%) are: (1) Disagreeing utterance: 'Not true' (buhui la), 'Not really, you are flattering me' (35.1\%); (2) Downgrade: 'He is so stupid' (ta zhen ben) (9.6\%); (3) Expressing doubt: 'Really?' (shima?)(7.0\%); (4) Rebuttal: 'Don't exaggerate.' (bu yao kuazhang)(1.3\%).

The different ways of Deflect or Evade (24.2\%) are: (1) Avoid compliment but answer question: When complimented on dress and asked where it was from, the response was '...bought in London' (zai Lundun mai de)(9.1\%); (2) Informative comment: When complimented on cooking skills, one recipient responded 'My sister taught me' (wo jiejie jiao wo de)(7.4\%); (3) Return compliment, e.g. 'Your son is the clever one' (ni de erzi cai lihai)(3.0\%); (4) Offering object of compliment e.g. 'Eat more' (duo chixie)(2.2\%); (5) Expressing embarrassment, e.g. 'I am embarrassed' (wo zhen bu hao yisi) (1.7\%); (6) Joking: When complimented on smart dress, a response was 'Of course, I have a beautiful figure' (dangran, wo de shencai hen mei) (0.8\%).

The different ways of Acceptance (22.8\%) are: (1) Neutralizing utterance, e.g. 'It's okay' (hai keyi) (10.9\%); (2) Smile (10.9\%); (3) Appreciation: 'Thank you' (xiexie) $(1 \%)$.

Studies have shown that the extent to which a compliment is accepted or rejected differs in different cultures. Holmes (1988a: 496) shows that New Zealanders' most common response to compliments is ACCEPT, which may involve qualification (Holmes 1995: 139). There are several cross-cultural studies on compliment responses. Herbert (1989, 1991) and Herbert and Straight (1989) contrasted compliments and responses in South African and American English. They find that American English has a higher frequency of compliments and that the preferred response type is other than acceptance. This is attributed to the fact that the US has a more egalitarian and democratic society than that of South Africa. In South African English compliments are infrequent and responses tend to be that of acceptance. In comparing Polish and British

\footnotetext{
${ }^{10}$ Wieland has argued that due to the influence of Catholic ideology in which pride is a sin, the French have difficulty in accepting compliments. (Wieland 1995).
} 
English, Lewandowska-Tomaszczyk (1989) concluded that compliments were more frequently acknowledged and accepted in British English than in Polish, which showed a preference for downgrading responses. Compliments are accepted more often in British English than in Finnish (Ylänne-McEwen 1993). In contrasting German and American compliment responses, research has shown that for Americans, social factors are more important than the truthfulness of their compliments, whereas Germans seem to be more oriented towards the truthfulness and content of the language than toward its social function (Byrnes 1986; Golato 2002).

Almost all studies on responses to compliments in Chinese have shown that rejection is the most frequent. When comparing responses to compliments between speakers of American English and Chinese, Chen's (1993) findings show that American English speakers tend to accept compliments, thus adhering to Leech's Agreement Maxim (1983). In contrast, the $96 \%$ rejection rate from Chinese speakers is seen as being motivated by Leech's Modesty Maxim (1983). Chen (1993) and Yu (2003, 2005) attribute this difference to the differences in social values between the two cultures. Gu (1990) proposes the Self-Denigration Maxim stating that for the Chinese, it is polite to (a) denigrate self and (b) elevate others. Ye (1995) maintains that the non-acceptance response to compliments among Mandarin Chinese speakers carries a pragmatic force of acceptance covered by a semantic form of disagreement. The next section discusses the four subcategories of non-acceptance.

\section{Non-acceptance}

There are four subcategories in the non-acceptance category: Disagreeing utterance/frozen expression, downgrading, expressing doubt, and rebuttal. This is made apparent in Table 2, which also shows the general pattern of distribution of gender and generation in compliment and response.

Table 2. Non-acceptance categories, complimenters and responders (sample size $=150$ )

\begin{tabular}{llcccc}
\hline & NON-ACCEPTANCE categories & $\%$ & \multicolumn{3}{c}{ Complimenters-Responders } \\
1. $\begin{array}{l}\text { Disagreeing utterance/frozen } \\
\text { expressions }\end{array}$ & 35.1 & F-F & F-f & F-m \\
2. & Downgrading & 9.6 & F-F & & M-M \\
3. & Expressing doubt & 7.0 & F-F & f-f & \\
4. & Rebuttal & 1.3 & F-F & f-f & \\
& Total & $\mathbf{5 3 . 0}$ & & &
\end{tabular}

\subsection{Disagreeing utterance: Denial and convention}

The above table shows that disagreement is the largest category under Non-acceptance. The first types of disagreeing utterances are utterances such as meiyou (lit. 'don't have'), meiyou la (lit. 'don't have la'), and buhui la (lit. 'not able la') or utterances prefaced by these disagreeing phrases. Most responses of this sort come from $f$ when responding to 
F's compliments on their appearance. An example is given in (4) in which a female university student is complimented by her aunt:

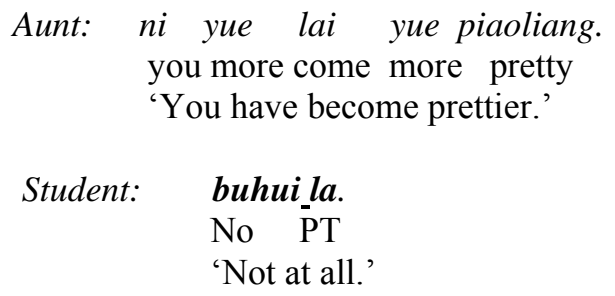

' $L a$ ' is a pragmatic particle in Singapore colloquial speech (see Gupta 1992). In this case, la has the effect of softening the denial. For example, in the context of responding to compliments in Singapore Mandarin, 'meiyou' (lit. don't have) means 'it's not true', 'meiyou la' would mean 'it's not really true'. This type of disagreeing utterance makes up a total of 58\%: 'buhui la' makes up 7\% while the 'meiyou/meiyou la' makes up 51\%.

$\begin{array}{lll} & \text { 不会啦 } & \text { 没有/没有啦 } \\ & \text { bu hui la } & \text { meiyou / meiyou la } \\ \text { Literal meaning } & \text { not able la } & \text { not have/ no have la } \\ \text { Pragmatic meaning } & \text { It's not really true } & \text { It's not really true } \\ & 7 \% & 51 \%\end{array}$

$($ Total $=58 \%)$

The other types of disagreeing utterances are questions such as 'nali' (lit. 'where', meaning: 'not true'), 'nali you' (lit. 'where have' or 'where got', meaning: 'not true'), and 'nayou' which is a short form of 'nali you'. They are uttered with rising interrogative intonation. The primary illocutionary act is a question but the secondary illocutionary act is a denial. An example of such a disagreeing utterance is given in (5). In this example, a student's fifth aunt compliments on her second aunt's daughter's weight loss. The second aunt denies this by using the phrase 'mana wu'; 'mana' is 'where' in Malay, here functioning as a Malay loan word in Hokkien, while ' $w u$ ' is 'have' in Hokkien. Together 'mana wu' in Singapore Hokkien ${ }^{11}$ is equivalent to' nali you' in Mandarin. She also continues to downgrade her own daughter.

\section{(Spoken in Hokkien)}

Fifth auntie: li eh xiaoling asi. Yi jibai sang liao jinzue. You POS Xiaoling also she this time thin ASP much

Second Aunt: mana wu yi ah wu si bui wu si sang Where have she EX have time fat you time thin

$$
\text { jinzun yi gor bui liao }
$$

\footnotetext{
${ }^{11}$ Singapore Hokkien has many Malay loan words due to historical reasons and language contact.
} 
Now she again fat ASP

Mum's fifth younger sister: 'Your Xiaoling too has lost a lot of weight.

Mum's second sis: 'Not true at all! She is sometimes fat and sometimes thin. Now she is fat again.'

This form of non-acceptance makes up 39\% of the disagreeing utterances.

$\begin{array}{llll} & \text { 哪里? } & \text { 哪里有? } & \text { 哪有? } \\ & \text { nali? } & \text { nali you? } & \text { na you? } \\ \text { Literal meaning } & \text { where } & \text { where have } & \text { where have } \\ \begin{array}{l}\text { Pragmatic meaning } \\ \text { (Total = 39\%) }\end{array} & \text { not true } & \text { not true } & \text { not true } \\ & & & \end{array}$

The above two types of disagreeing utterances are used interchangeably. Generally speaking, there is no difference between the two in meaning. However, the data shows that when a person is complimented on his girlfriend or her boyfriend, the response is usually the second type of disagreeing utterance.

The remaining $3 \%$ of disagreeing utterances expresse disagreement in other ways such as: 'bie kai wanxiao le' ('Be serious!') or 'bu suan la' ('Not really so').

\subsection{Conventionality of non-acceptance}

A survey has been carried out in which 250 first-year students majoring in Chinese Studies were given examples from the four categories of non-acceptance responses. Each questionnaire had 16 pairs of compliments and their responses. The students were told that these compliments and responses were exchanged during CNY visits. Information on the relationships between complimenters and complimentees was also provided. The students were told to judge based on their native speakers' intuition whether the respondents genuinely did not agree with the compliment or whether rejections were only a conventional response. The results show that non-acceptances are largely judged to be a conventional response rather than a genuine rejection: The results for "conventional non-acceptance" for each category are: Disagreeing utterance $66 \%$, downgrade $60 \%$, expressing doubt $67 \%$, rebuttal $55 \%$.

It is obvious from this survey that although rejection to compliments is the most preferred response, this does not necessarily mean that respondents truly reject the compliment. On the contrary, most respondents who rejected the compliments are believed to have done so conventionally rather than out of belief that the compliment is untrue. This is related to what Ma (1996) proposes; namely that "yes" is "no" and "no" is "yes" for the Chinese. There is a Chinese saying that people usually behave in a manner of koushixinfei literally 'mouth agrees but heart disagrees' which means that one may say one agrees with something but in one's heart, one does not agree. Here we see this behavior working in the opposite direction of koufeixinshi literally 'the mouth rejects but the heart accepts'. Since it is seen as 'polite' to reject compliments, the complimentee conventionally rejects the compliment, but internally may accept it with secret joy. This is typical of Chinese politeness culture. 
Non-acceptance is a conventional response aimed at redressing the status balance between the interlocutors which has been altered through the compliment. The compliment has raised the addressee to a higher status and its rejection attempts to restore the balance. Therefore, more often than not, non-acceptances or rejections are conventionally used to this effect and do not retain their literal meaning.

\subsection{Conventional strategies: Downgrading, expressing doubt, rebuttal}

When a mother receives a compliment on her child's achievement, she is likely to respond with: 'Your child is smarter, mine is dumb'. She is doing the polite thing to praise the complimenter's child and downgrade her own child. Among Chinese families, the child's success and failure reflect on the parents' success and failure, so by downgrading one's own child and praising the other's child, the complimentee elevates the position of the complimenter.

The data shows that downgrading is a favorite strategy of F (59.0\%) especially when they are complimented on their children. The second group that uses this strategy is M (23.0\%). For Brown and Levinson (1987: 178), "giving deference" is a negative politeness strategy realized as humbling oneself and elevating the other. Gu (1990) says that the practice of downgrading is self-humbling, which is a positive virtue in the Confucian ethics. What is interesting here is that the compliment-giver seldom expects the hearer to agree with the compliment, especially if they are not peers and not familiar with one another. In fact, it would shock the complimenter and those who hear him/her if the complimentee agrees, a response which would immediately seem proud. As Biq (1984) points out, a Chinese tries to be a good host by verbally deprecating the food presented. This type of conventionalization allows the speaker the freedom of coming up with different utterances so long as the strategy is properly chosen.

In example (6), Female A compliments cousin B on her daughter's ability to study computer science, B responds that her daughter is only in the polytechnic (a tertiary institution regarded as less prestigious than a university) and that she is not as smart as A's daughter. B's answer thus conveys the role-playing implications of downgrading her daughter as a humble receiver of the compliment. There is codeswitching from Mandarin to Malay here. The word 'banlai' is from the Malay word 'pandei', which means 'smart' or 'clever'. This code-switch is usually done to emphasize the 'smartness'. The word 'poly', short for polytechnic, is also a code-switch from Mandarin to English. Since the general education system in Singapore is Englishmedium, most of these education terms are in English even in Mandarin conversations (Lee 2003).

(6) Female cousin A: Ni de nüer cai banlai la du diannao hor You POS daughter then clever PT study computer PT 'Your daughter is the smart one, studying computer science.'

Female cousin B: du poly eryi ma nali you ni nuer lihai Study poly only PT where have you daughter clever 'Only studying in the polytechnic, not as smart as your daughter.' 


\section{Acceptance}

Acceptance responses is the lowest category, it makes up $22.8 \%$ of the total responses. There has not been a single response in the data that could exemplify blunt acceptance, such as 'Yes, I think it is beautiful too', or 'Yes, it is gorgeous'. The 'acceptance' replies in the data are more subdued, allowing the hearer to agree with the compliment giver in a subtle way without violating his/her role as a humble compliment recipient. Table 3 shows the three subcategories under ACCEPTANCE with regard to gender and generation. The two popular ways to accept a compliment are 'smiling' and 'neutralizing utterance'.

Table 3. Acceptance categories, complimenters and responders (sample size $=70$ )

\section{ACCEPTANCE categories $\quad \% \quad$ Complimenters-Responders}

1. Neutralizing utterance

10.9

F-F

2. Smile

10.9

3. Appreciation/Frozen expression

1.0

F-f

Total

22.8

\subsection{Neutralizing utterance}

These are responses that show reluctant agreement, such as 'It's quite OK.' Most of these responses are from $\mathrm{F}$ when responding to compliments referring to their children. Although it is the convention to deny and downgrade a compliment, this is a smart strategy that allows the complimentee to accept the compliment in an acceptable way. These responses consist of hedges and usually come in the following forms: 'hai hao la', 'hai keyi' la, 'chabuduo la'. They all mean 'well, it's ok' or 'well, it's all right' with a connotation of reluctant concession.

$\begin{array}{llll} & \text { 还好啦 } & \text { 还可以啦 } & \text { 差不多啦 } \\ & \text { hai hao la } & \text { hai keyi la } & \text { chabuduo la } \\ \text { Literal meaning } & \text { still good PT } & \text { still able PT } & \text { miss not much PT } \\ \text { Pragmatic meaning } & \text { passable } & \text { quite all right } & \text { quite ok }\end{array}$

An example of this neutralizing utterance is as follows:
First Aunt: $\quad$ Wa ni de lao da hen congming hor, daxue sannianji liao. Wow you POS old big very smart PT university third year ASP 'Wow, your eldest daughter is very smart. She is already in her final year in the university.'

Youngest Aunt: hai hao la.

Still good PT 
'It's ok.'

\subsection{Smile}

The fs use 'smile' as a strategy to respond to compliments mainly from Fs. These compliments are usually about physical appearance, such as having lost weight and looking more beautiful than before. To be polite to $\mathrm{F}$, their younger counterparts either deny the compliment as mentioned before or simply smile. Since seniority is highly respected in Chinese culture, Fs have the liberty to say almost whatever they like while the role of fs is mainly to acknowledge. ${ }^{12}$

\subsection{Appreciation/frozen expression}

Appreciation refers to appreciation tokens like 'thank you'. All these responses come from fs and ms responding to their seniors.

\section{Deflect or evade}

Instead of accepting or rejecting the compliment, the hearer chooses to avoid responding directly to the compliment by using the deflect or evade strategies listed in Table 4. According to Grice's cooperative principle, when the hearer does not reply directly to the compliment, one has to look for the implied meaning. When the complimentee uses deflect or evade strategies, more often than not, the implied meaning is an affirmative one. This is because it is not polite to accept directly, hence one tends to use other strategies such as deflect or evade to 'accept'. These strategies allow the hearer to avoid uttering words of acceptance but imply acceptance by directing attention elsewhere. Thus, they will still be seen as achieving the expected 'politeness'.

Table 4. Deflect or evade categories, complimenters and responders (sample size $=70$ )

DEFLECT or EVADE categories $\quad \% \quad$ Complimenters-Responders

1. Answer question

$9.1 \quad$ F-F $\quad$ f-f

2. Informative comment

$7.4 \quad$ F-F

$\mathrm{m}-\mathbf{M}$

3. Return compliment

$3.0 \quad$ F-F

4. Offering object of compliment

2.2 F,M,f,m-F

5. Embarrassed

1.7

F,M,f-f

F-m

\footnotetext{
${ }^{12}$ Students from China say that given the same situation, they usually respond with words rather than only with a smile. This shows that there are variations among different Chinese-speaking societies.
} 


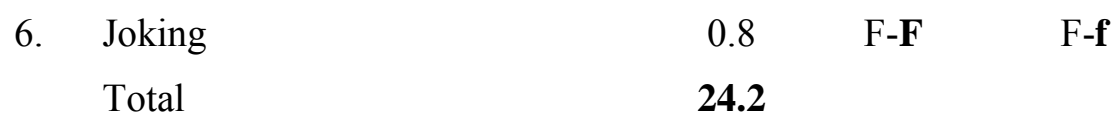

\subsection{Answer question}

A speaker compliments a hearer on the dress she is wearing and asks where it is bought. The hearer will give information about where it is bought without acknowledging the compliment. Such questions are usually asked to show that the dress is pretty rather than seeking for information as seen in Polish compliments (Jaworski 1995). The example below shows that when $\mathrm{f}$ is complimented on losing weight, followed by the question of whether she has a boyfriend, she chooses to answer the question and avoids responding to the compliment.

(8) (Spoken in Hokkien)

Second Aunt: jizun ju sang, ngia liao lo, now more slim pretty ASP PT

wu dabo pengyou liao bue?

have boy friend ASP QN

'You have slimmed down and become prettier. Do you have a boyfriend?'

Niece: $\quad a$ ? boh la!

PT no PT

'What? No.'

\subsection{Informative comment}

Informative comment refers to responses like 'A friend taught me how to do this'. The implicature drawn from such informative comments is that the hearer agrees with the compliment yet at the same time, s/he avoids self-praise by shifting the credit to some other referent. This is a clever solution to the conflict between the speaker's acceptance of the compliment and his/her sensitivity to self-praise avoidance (e.g. Pomerantz 1978; Holmes 1988; Herbert 1989).

\subsection{Return compliment}

The return compliment is mostly used by Fs when they are complimented on their children. Example (9) is a typical example when A compliments her sister and the sister responds with a similar compliment. In the response, there is a code-switch to English in the proper noun 'RI' (Raffles Institution) which is regarded as the top boys' school in Singapore. (Note the prestige placed on good schools in the speech community). 
younger sister: wa ni san ge dou name da le, hao ming hor, keyi xiang fu le. PT you three CL all so big ASP good life PT can enjoy blessing ASP 'Wow, all your three children are so grown up, good life, you can enjoy life now?'

older sister: $\quad$ meiyou la, ni de bushi geng lihai, da de jin RI le!

no PT yours not more clever eldest enter RI PT

'No, yours are even cleverer, the eldest one is in RI!'

In returning the compliment, the hearer implies that she agrees with the compliment. At the same time, the recipient suggests that the complimenter is also worthy of an equivalent compliment. This strategy allows the hearer to reduce the complimentary force as well as repay the complimenter. In this way, s/he not only acts out the role of the humble compliment recipient but also applies the Balance Principle of repaying a debt (in this case, a compliment) proposed by Gu (1990).

\subsection{Offering object of compliment}

During CNY, eating is a common activity. When someone compliments the host on the good food, it is common to hear utterances such as 'Eat more if you like it.' Instead of acknowledging directly that the food is good, the hearer accepts the compliment by turning the speaker's attention to the complimented object and by offering more of it. (To Chinese, the primary illocutionary act of complimenting the food is usually interpreted as the secondary illocutionary force of asking for more but being too embarrassed to ask directly).

\subsection{Expressing embarrassment}

Expressing embarrassment includes responses like 'Don't embarrass me' (bie rang wo bu hao yisi). This strategy addresses the impact of the compliment rather than its acceptance or rejection. The data shows that this response to compliments only comes from the younger generation, i.e. fs and $\mathrm{ms}$, when they are complimented by the older generation.

\subsection{Joking}

Joking is also found as a compliment response. For instance, when a complimenter compliments on the dress the complimentee is wearing, s/he responds 'Look who's wearing the dress.' (i.e. because I am wearing the dress, the dress looks good). This type of response is usually accompanied with laughter and is used between close friends. These responses thus seem to presuppose solidarity and intimacy between the parties. In using an 'upgrade' reply, the hearer assesses the relationship with the complimenter and decides that the latter will not be offended by this remark. Hence, though these utterances seemingly violate the need to avoid self-praise, their exaggerated and humorous features may offset the impact of self-praise that they literally suggest. These 
are usually responses given to peers. Cross-cultural studies on compliment responses between British and Spanish university students show that Spanish males tended to upgrade compliments ironically, a type of compliment response absent from the British data. (Lorenzo-Dus 2001).

Finally, it should be mentioned that there are no 'no acknowledgement' responses (Herbert 1990: 213) ${ }^{13}$. This is because during CNY visits, many of these relatives visit one another only once a year, they are not on close terms with one another and therefore will try to be as polite as they can. To ignore a compliment is in effect to ignore the complimenter, which is considered rude. Due to this consideration, complimentees do not usually ignore; instead, they would at least smile or choose one of the above evading strategies to wriggle out of the embarrassing situation.

\section{Conclusion}

This paper has explored compliments and compliment responses in the Singapore Chinese community during CNY, when it is customary for relatives to visit one another. Unlike most other studies on Chinese compliments which use constructed data, we collected natural data from a specific setting governed by specific conventions of behavior, one of which is the exchange of compliments. Since this is a traditional setting, we can assume that traditional values will be reflected in people's practices. Our results show that this is indeed the case. First of all, it appears that married females (Fs) with children are the main givers and recipients of compliments. They are the ones who should know best and behave according to Chinese social expectations and conventions. Interestingly, the main topic of compliments in this context is each other's children. This includes the children's academic achievements, career success, having children (or grandchildren) and filial piety. Academic success presumably leads to better career opportunities, which may lead to better income and more possessions and a more comfortable lifestyle for both children and parents. Thus, the socioeconomic status is important as well as getting married and having children, which is in turn associated with socioeconomic status because of the cultural expectation that children will assume responsibility for the financial security of their parents in old age.

In relation to compliment responding, in this Chinese-speaking community, the preferable strategy appears to be that of non-acceptance. This finding is in line with results from other studies and has been attributed to modesty, a value which is of utmost importance in Chinese politeness ( $\mathrm{Gu}$ 1990; Chen 1993). However, what has been argued here is that such responses are largely conventionalized and have lost their literal meaning. Most of the responses to compliments in this study indicate that they conform to conventional expectations rooted in Chinese culture rather than being genuine expressions of disagreement and rejection. This is especially so when these interactions are between relatives and friends that one visits only during CNY. The relationships between these people are more often cordial rather than intimate. Due to the rather

${ }^{13}$ Herbert (1990: 213) categorizes 'no acknowledgement' under NON-AGREEMENT. 
distant relationships and bearing in mind the importance of showing respect to the older generation, people are even more cautious in behaving according to expectations. The more distant the relationships are, the more indirect and conventionalized their interactions will be. As noted by Searle (1971: 46) in his discussion of speech acts, "Meaning is more than a matter of intention, it is also a matter of convention". In summary, this paper has shown that the speech event of complimenting and compliment responding in Singapore Chinese when understood in its given setting (in this case CNY) will yield meaning results - compliments are mainly phatic, responses are largely conventionalized, and the values reflect the appreciation for children's academic and socioeconomic success.

\section{References}

Biq, Y.-O. (1984) Indirect speech acts in Chinese polite expressions. JCLTA 19.3: 1-10.

Boyle, R. (2000) You've worked with Elizabeth Taylor!: Phatic functions and implicit compliments. Applied Linguistics 21/1: 26-46.

Brown, P., and S. Levinson (1978) Universals in language usage: Politeness phenomena. In E. Goody (ed.), Questions and politeness. Cambridge: Cambridge University Press, pp. 56-234.

Brown, P., and S. Levinson (1987) Politeness: Some universals in language usage. Cambridge: Cambridge University Press.

Byrnes, H. (1986) Interactional style in German and American conversations. Text 6: 189-206.

Chen, R. (1993) Responding to compliments: A contrastive study of politeness strategies between American English and Chinese speakers. Journal of Pragmatics 20: 49-75.

Du Bois, J.W. et. al. (1993) Outline of discourse transcription. In J.A. Edwards and M.D. Lampert (eds.), Talking Data: Transcription and Coding in Discourse Research. New Jersey: Lawrence Erlbaum Associates Publishers, pp. 45-89.

Goffman, E. (1955) On face-work: An analysis of ritual elements in social interaction. Psychiatry. Journal of the Study of Interpersonal Processes 18.3: 213-231.

Goffman, E. (1967) Interaction ritual: Essays in face-to-face behavior. New York: Pantheon Books.

Golato, A. (2002) German compliment responses. Journal of Pragmatics 34: 547-571.

Grice, P. (1975) Logic and conversation. In P. Cole, and J. Morgan (eds.), Syntax and semantics, vol. 3: speech acts. New York: Academic Press, pp. 41-58.

Grice, P. (1989) Strides in the way of words. Cambridge: Harvard University Press.

Gu, Y. (1990) Politeness phenomena in modern Chinese. Journal of Pragmatics 14.2: 237-257.

Gupta, A.F. (1992) The pragmatic particles of Singapore Colloquial English. Journal of Pragmatics 18: 31-57.

Herbert, R.K. (1989) The ethnography of English compliments and compliment responses: A contrastive sketch. In W. Oleksy (ed.), Contrastive pragmatics. Amsterdam: John Benjamins Publishing Company, pp. 3-35. 
Herbert, R.K. (1990) Sex-based differences in compliment behavior. Language in Society 19: 201-224.

Herbert, R.K. (1991) The sociology of compliment work: An ethnocontrastive study of Polish and English compliments. Multilingua 10: 381-402.

Herbert, R.K. (1997) The sociology of compliment work in Polish and English. Multilingua 10.4: 381402.

Herbert, R.K., and H. Straight (1989) Compliment-rejection versus compliment-avoidance: Listenerbased verus speaker-based pragmatic strategies. Language and Communication 9: 35-47.

Ho, D.Y. (1975) On the concept of face. American Journal of Sociology 81.4: 867-884.

Hu, H.C. (1944) The Chinese concepts of 'face'. American Anthropologist 46.1: 45-64.

Holmes, J. (1988a) Compliments and compliment responses in New Zealand English. Anthropological Linguistics 28: 485-508.

Holmes, J. (1988b) Paying compliments: A sex-preferential politeness strategy. Journal of Pragmatics 12: 445-465.

Holmes, J. (1993) New Zealand women are good to talk to: An analysis of politeness strategies in interaction. Journal of Pragmatics 20: 91-116.

Holmes, J. (1995) Women, Men and Politeness. London and New York: Longman.

Jucker, Andreas H. (2009) Speech act research between armchair, field and laboratory: The case of compliments. Journal of Pragmatics 41: 1161-1635.

Jaworski, A. (1995) 'This is not an empty compliment!' Polish compliments and the expression of solidarity. International Journal of Applied Linguistics 5.1: 63-94.

Knapp, M.L., R. Hopper, and R.A. Bell (1984) Compliments: A descriptive taxonomy. Journal of Communication 34.4: 12-31.

Laver, J.D.M.H. (1975) Communicative functions of phatic communion. In A. Kendon, R.M. Harris, and M.R. Key (eds.), The Organization of Behavior in Face-to-Face Interaction. The Hague: Mouton.

Laver, J.D.M.H. (1981) Linguistic routines and politeness in greeting and parting. In F. Coulmas (ed.), Conversational Routine: Explorations in Standardized Communication Situations and Prepatterned Speech. The Hague: Mouton.

Lee, C. (1990) Cute yaw haiya-nah! Hawaii Creole English compliments and their responses: Implications for cross-cultural pragmatic failure. University of Hawaii Working Paper in ESL 9.1: 115161.

Lee, C.L. (2003) Motivations of code-switching in multi-lingual Singapore. Journal of Chinese Linguistics 31.1: 145-176.

Leech, G. (1983) Principles of Pragmatics. London: Longman.

Lewandowska-Tomaszczyk, B. (1989) Praising and complimenting. In W. Oleksy (ed.), Contrastive Pragmatics Amsterdam: John Benjamins Publishing Company, pp. 73-100.

Lorenzo-Dus, N. (2001) Compliment responses among British and Spanish university students: A contrastive study. Journal of Pragmatics 33: 107-127. 
Ma, R. (1996) Saying “yes" for "no" and "no" for "yes": A Chinese rule. Journal of Pragmatics 25: 257266.

Manes, J. (1983) Compliments: A mirror of cultural values. In N. Wolfson, and E. Judds (eds.), Sociolinguistics and Language Acquisition. M.A.: Newbury House, Rowley, pp. 96-102.

Manes, J., and N. Wolfson (1981) The compliment formula. In F. Coulmas (ed.), Conversational Routine: Explorations in Standardized Situations and Prepatterned Speech. The Hague: Mouton.

Mao, L.R. (1994) Beyond politeness theory: 'face' revisited and reviewed. Journal of Pragmatics 21.5: 451-486.

Morgan, J.L. (1978) Two types of convention in indirect speech acts. In P. Cole, and J. Morgan (eds.), Syntax and semantics, vol. 3: speech acts. New York: Academic Press, pp. 261-280.

Pomerantz, A. (1978) Compliment responses. In J. Schenkein (ed.), Studies in the organization of Conversational Interaction. New York: Academic Press, pp. 79-112.

Searle, J.R. (1971) What is a speech act? In J.R. Searle (ed.), Philosophy of language. London: Oxford University Press, pp. 39-53.

Searle, J.R. (1975) Indirect speech acts. In P. Cole, and J. Morgan (eds.), Syntax and semantics, vol. 3: speech acts. New York: Academic Press, pp. 59-82.

Sifianou, M. (2001) "Oh, how appropriate" compliment and politeness. In A. Bayraktaroğlu, and M. Sifianou (eds.), Linguistic politeness across boundaries: The case of Greek and Turkish. Amsterdam: John Benjamins Publishing Company, pp. 391-430.

Singapore Department of Statistics 2009. http://www.singstat.gov.sg/ (last accessed 29 Oct 2009).

Tang, C.-H., and G.Q. Zhang (2009) A contrastive study of compliment responses among Australian English and Mandarin Chinese speakers. Journal of Pragmatics 41.2: 325-345.

Tu, W. (1984) Confucian Ethics Today: The Singapore Challenge. Singapore: Federal Publications (S) Pte. Ltd.

Tu, W. (1985) Selfhood and otherness in Confucian thought. In A.J. Marsella, G. DeVos, and F.L.K. Hsu (eds.), Culture and self: Asian and western perspectives. New York: Tavistock Publications, pp. 231-351.

Watts, R.J. (2003) Politeness. Cambridge: Cambridge University Press.

Wieland, M. (1995) Complimenting behavior in French/American cross-cultural dinner conversations. The French Review 68.5: 796-812.

Wolfson, N. (1983) An empirically based analysis of complimenting in American English. In N. Wolfson, and E. Judd (eds.), Sociolinguistics and language acquisition. Rowley, MA: Newbury House, pp. 82-95.

Wolfson, N. (1984) Pretty is as pretty does: A speech act view of sex roles. Applied Linguistics 5.3: 236244.

Wolfson, N., and J. Manes (1980) The compliment as a social strategy. Papers in Linguistics 13: 391-410.

Ye, L. (1995) Complimenting in Mandarin Chinese. In Gabriele Kasper (ed.), Pragmatics of Chinese as native and target language. Hawaii: Second language and teaching curriculum center, Honolulu, pp. 207278. 
Ylänne-McEwen, V. (1993) Complimenting behaviour: A cross-cultural investigation. Journal of Multilingual and Multicultural Development 14.6: 499-508.

Yu, M. (2003) On the universality of face: Evidence from Chinese compliment response behavior. Journal of Pragmatics 35: 1679-1710.

Yu, M. (2005) Sociolinguistic competence in the complimenting act of native Chinese and American English speakers: A mirror of cultural values. Language and Speech 48.1: 91-119.

Yuan, Y. (2002) Compliments and compliments responses in Kunming Chinese. Pragmatics 12.2: 183226.

\section{Appendix : List of abbreviations used}

$\begin{array}{ll}\text { ASP } & \text { Aspect marker } \\ \text { BE } & \text { Copular } \\ \text { CL } & \text { Classifier } \\ \text { EX } & \text { Exclamation } \\ \text { POS } & \text { Possessive case } \\ \text { PT } & \text { Particle } \\ \text { QN } & \text { Question marker }\end{array}$

